\title{
CRÍTICA DE ARTE NA IMPRENSA CARIOCA DO SÉCULO XIX: REVISTA MUSICAL E DE BELLAS ARTES
}

Rosangela de Jesus Silva

Um panorama crítico:

(...) a crítica de arte, por mais inadequada que seja, responde a uma necessidade de compreender o fenômeno artístico e a um desejo de compartilhar o julgamento que se emite sobre as obras. Pode-se demonstrar sua impossibilidade, mas deve-se constatar sua existência.

O fenômeno artístico e sua compreensão vêm sendo perseguido pelo homem há muitos séculos. Talvez nunca cheguemos à sua totalidade. Porém certamente, assim como afirma Richard, temos que constatar que o esforço de compreensão existe.

A história da arte nos mostrou que muitos equívocos foram cometidos, seja com julgamentos "errôneos" ou com a ausência deles. Sabemos que a crítica possui um poder de impulsionar ou desacreditar obras e artistas, ficando assim latente a individualidade e o gosto. Como historiadores buscamos muitas vezes fazer a mea culpa e resgatar os "esquecidos". Tarefa por vezes penosa, entretanto necessária. Não queremos aqui abrir a discussão do lugar do crítico e do historiador, mas sim tentar ver a atuação da crítica em um determinado tempo e lugar, já que seu peso, segundo Argan, vem aumentando bastante desde a segunda metade do século XIX.

O alto grau de especialização e o peso cultural cada vez maior da crítica de arte, na segunda metade do século passado e especialmente no nosso, demonstram que esta responde a uma necessidade objetiva e não pode ser considerada uma actividade secundária ou auxiliar relativamente à própria arte.(...)

O tempo a que vamos nos referir é o século XIX, no qual a arte e crítica francesa tiveram um grande peso, principalmente em nosso meio, quando constatamos que o primeiro órgão institucional voltado para as

\footnotetext{
1 Rosangela de Jesus Silva desenvolve sua pesquisa de doutorado com financiamento da Fundação de Amparo à Pesquisa do Estado de São Paulo/FAPESP.

Uma versão resumida desse texto foi publicada na revista eletrônica Dezenove\&vinte.
} 
artes em nosso país foi composto pela Missão Francesa de Le Breton, por sinal, crítico de arte.

Nomes como Baudelaire, Sthendal, Guizot, Quatremère de Quincy, Valenciennes, Delecluze, Zola, Gustave Planche, Thoré, Charles Blanc, Théophile Gauthier, entre muitos outros nos remetem imediatamente para as discussões do século XIX em torno do Neoclassicismo, do Romantismo, do Realismo, do Idealismo, enfim das idéias estéticas que permearam a produção artística naquele período. Idéias que em grande medida influenciaram a crítica no Brasil, já que a França e tudo o que ela representava foi muito importante no âmbito cultural brasileiro.

Para Sartor o século XIX na América Latina recebeu de forma diferente as transformações artísticas vivenciadas na Europa. É como se tudo passasse por um filtro e aqui se adequasse a sua maneira.

Se na Europa, a marca de passagem à modernidade foi, entre outros aspectos, dado pela vocação de uma arte naturalística e anti-academica que interessou primeiro os impressionistas, na América tal sentido permanece pelo menos confuso e incerto. $\mathrm{O}$ acolhimento das instancias realistas e naturalistas, que nos melhores artistas se acompanhou de uma elaboração autônoma da matéria pictórica (...) não foi, todavia sinônimo de mudança radical e de verdadeira modernização.(...)

Contudo pensar o caso brasileiro nos apresenta algumas particularidades indispensáveis à compreensão desse fenômeno.

Um primeiro ponto muito importante a ser considerado é a ausência de grandes autoridades e de um veículo de divulgação específico para a crítica, pois embora já com Manuel de Araújo Porto Alegre a preocupação com a questão artística tivesse tomado uma proporção maior. Porto Alegre foi crítico, buscou reformular o ensino da Academia-Reforma Pedreira-, bem como pensava numa produção artística de caráter brasileiro, além de ter tido importante papel no IHGB - Instituto Histórico e Geográfico Brasileiro, criado em 1838, o qual foi uma iniciativa de reflexão da questão nacional em seus aspectos mais amplos, com grande interesse, segundo Mário Barata, no nosso passado e presente artístico. Porém, só teremos um periódico dedicado às belas artes em 1879, que foi a Revista Musical e de Belas Artes, a qual como já diz o título também tratava da questão musical considerada a frente das artes em termos de desenvolvimento e novidades, assim como do teatro. Esse periódico teve curta duração, dois anos, porém, acreditamos que tenha sido um importante meio de divulgação e debates artísticos. Voltaremos a ele com mais vagar um pouco mais à frente. 
Somente na década de oitenta teremos publicado um livro dedicado a fazer crítica no Brasil que é o livro de Felix Ferreira Belas artes: Estudos e apreciações, publicado em 1885. Seu intuito é a análise da produção artística daquele momento. Ferreira apresenta a seguinte opinião sobre as exposições:

(...) as exposições concorrem para apurar o bom gosto público, e enquanto este não estiver na altura das sociedades cultas, a arte não passará entre nós de passatempo.

Depois desse livro, em 1888, Gonzaga Duque Estrada publica $A$ arte Brasileira. Livro até hoje referência para o estudo da arte no século XIX brasileiro. Segundo Chiarelli em sua introdução de A Arte Brasileira, Duque Estrada procurou pensar a arte brasileira além do ambiente carioca buscando uma dimensão maior da cultura nacional.

(...) $\mathrm{O}$ autor desejava refletir sobre em que medida a produção visual aqui levada a cabo corresponderia às necessidades intrínsecas da nação brasileira, da cultura aqui produzida.

O pensamento de Duque Estrada, fortemente influenciado por $\mathrm{H}$. Taine, via no estudo a grande redenção do artista.

Em um país colocado nas atuais circunstancias em que se acha o Brasil, só estudos longos e muita meditação podem elevar o artista à sua merecida posição e dar-lhe os elementos para a sua independência de pensar e agir. (...)

Todo o debate se dava por meio da imprensa da época. Em sua grande maioria os artigos não eram assinados, mas sim identificados por pseudônimos, o que na época poderia ter dado maior liberdade nas falas, no entanto, escondeu personagens impedindo-se várias identificações precisas.

Outra questão relevante para tentarmos compreender essa crítica é o mercado das artes, ou melhor, a ausência dele. Tivemos naquele momento uma produção financiada, quase que exclusivamente, pelo governo. A própria criação da Academia de belas artes foi de responsabilidade governamental, com propósitos de oficialidade. Oficialidade que poderia direcionar a produção, não deixando espaço para uma arte de experimentação, independente e livre. Essa foi uma preocupação de parte da crítica que não via com bons olhos o exclusivismo do governo. Percebia-se a necessidade de criação de um mercado no qual os artistas tivessem outros patrocinadores e assim diversificassem a 
produção. Portanto, em torno do universo acadêmico foram geradas muitas críticas e reflexões sobre a arte nacional e sua organização.

Entre esses críticos figurou Angelo Agostini, suas críticas realizadas através de caricaturas e de textos nos mostram uma grande inquietação do artista para com as Belas Artes. Suas preocupações políticas, as quais perpassam toda a sua produção, também não ficam fora da questão artística, pelo contrário, dão o tom de suas opiniões. Algo realmente inédito nesse trabalho de Agostini é sua militância política, sua não isenção. Acreditamos que o trecho a seguir, extraído dos escritos de Baudelaire exemplifica o que poderia ser o espírito do crítico.

Eu creio sinceramente que a melhor crítica é a que é divertida e poética, não aquela fria e algébrica, que, com o pretexto de tudo explicar, não sente nem ódio nem amor, e se despoja voluntariamente de qualquer espécie de temperamento; mas sim - como um belo quadro é a natureza refletida por um artista -, a que será este quadro refletido por um espírito inteligente e sensível. (...) Quanto a crítica propriamente dita, espero que os filósofos compreendam o que vou dizer: para ser justa, isto é, para ter sua razão de ser, a crítica deve ser parcial, apaixonada, política, isto é, feita a partir de um ponto de vista exclusivo, mas de um ponto de vista que abra o maior número de horizontes.

Assim como nesse trecho Baudelaire defende a parcialidade, a paixão e a política, acreditamos que Agostini traz um pouco de tudo isso. Quando toma partido, por exemplo, na defesa de Pedro Américo que naquele debate florescido em 1879 representava o contra ponto da monarquia, ou quando critica a premiação realizada pela Academia de Belas Artes para os prêmios de viagem. Da mesma forma demonstra paixão pela obra de Rodolpho Bernardelli, quando lhe dedica páginas de textos e imagens sempre cobertos de elogios. $\mathrm{Na}$ vida pessoal, oferece sua filha para ser batizada pelo escultor, a depois também artista, Angelina Agostini. Uma relação de admiração, respeito e amizade.

Das páginas da Revista Ilustrada, seja através de hilariantes caricaturas ou de textos objetivos e mordazes, a cada número desferia violentos artigos contra tudo aquilo que no contexto social do Rio de Janeiro ou do Império lhe parecia injusto e descabido. As atividades de natureza cultural, sobretudo a música, o teatro e a pintura, mereciam atenção freqüente e eram consideradas sob a mesma perspectiva impiedosa que em geral assinalava a análise dos fatos políticos.

Angelo Agostini em sua crítica adiantou várias questões propostas por Gonzaga Duque, claro que o tom é diferente, Agostini figura um radicalismo ausente em Duque Estrada. Entre as considerações comuns figuram a importância do estudo para o artista se aperfeiçoar e as condições pouco favoráveis encontradas no Brasil. No trecho a seguir, destacado por Chiarelli, na introdução de $A$ Arte Brasileira é clara essa aproximação: 
... Em um país colocado nas atuais circunstâncias em que se acha o Brasil, só estudos longos e muita meditação podem elevar o artista a sua merecida posição de dar-lhe os elementos para a sua independência de pensar e agir.

Nas falas de Agostini é comum encontrarmos sua desilusão para com o ambiente artístico brasileiro considerado muito pobre, e sua constante exortação aos artistas para que procurem estudar e se aperfeiçoar e assim produzam de forma independente, afastados da academia. O Crítico faz sempre menção aos artistas que foram se aperfeiçoar, como Henrique Bernardelli, Firmino Monteiro, entre outros, da mesma forma que ao comentar determinada obra chama a atenção do artista para se dedicar mais ao estudo, pois este apresentaria deficiências que só o estudo e dedicação poderiam corrigir. É o caso, por exemplo, do pintor Castagnetto que tem um trabalho exposto na rua do ouvidor em 1887, o qual não foi identificado e recebeu do crítico o seguinte conselho:

Faça o possível para sahir do Rio de Janeiro e ir à Itália estudar.

E depois de muito estudar, verá que ainda tem muito que aprender, mas ao menos, pintará cem vezes melhor do que pinta hoje.

Nesse mesmo número da revista, em um outro artigo denominado Palestra, o crítico comenta a situação na qual se encontram as Belas Artes.

E', a todos os respeitos, lamentável a situação dos artistas no Brazil.

O publico, pouco preparado para o movimento artístico, nem sempre lhes dá os subsídios de que são dignos, e que se lhes tornam indispensáveis á vida.

O Estado, esse gasta alguma cousa, mas sempre movido pelo espírito político e pelos empenhos.

D'hai uma crise permanente, que obriga os artistas a abandonarem o seu ideal, a viajarem como mascates, e a cuidarem, em vez de obras de arte, de obras de encommenda.

\section{Um novo empreendimento crítico}

A produção artística brasileira vinha sendo tratada e comentada, conforme acima indicado, mesmo que de forma ainda tímida, através da imprensa desde a primeira metade do século XIX. Todavia ainda não tinha surgido um periódico que se destinasse exclusivamente para este fim, neste sentido, a Revista Musical, segundo o próprio texto de apresentação da revista, assume esta tarefa sem a pretensão de monopolizar este campo de atuação, mas com o claro propósito de se deter sobre as questões artísticas brasileiras. 
" $\mathrm{Na}$ falta de uma folha que tratasse especialmente das questões de musica e bellas-artes, era por todos conhecida.

(...)

Os paizes, ainda mesmo os mais atrazados neste ramo de conhecimentos, têm um ou mais orgãos especiaes que se occupão da arte, já cuidando do seu progresso e desenvolvimento, já registrando os commettimentos artísticos dos seus filhos, para o que achão insufficientes, pelo limitado espaço que dedicam a esta secção, os jornais políticos, noticiosos ou humorísticos.

Não nos illudimos com as pretenções de supprir de remédio infalível este mal. O que podemos asseverar é que, o que nos falta em força e competencia, sobeja-nos em diligencia e boa vontade."

Em seu primeiro ano, no número 15 a revista expressa a seguinte opinião sobre a crítica no Brasil:

Ninguém mais do que nós conhece o quanto são incompetentes os críticos de música e bellas-artes no nosso paiz; mas também o que conhecemos é que, bons ou mãos, estão a altura das obras que tem de criticar.

No Brazil, é certo, não há um Ruskin, um Planche, um Viardot, um Theophilo Gautier; mas também não é menos certo que não temos um Turner, um Delacroix, um Ingres, um Messonier.

Portanto: bons ou mãos, os nossos críticos, para o que têm de criticar - chegam!

A Revista Musical, assim chamada até o número 02, só vai receber o complemento $e$ de Bellas artes, a partir do número 03. Sua fundação foi um empreendimento dos músicos Arthur Napoleão e Leopoldo Américo Miguez, ambos nomes conceituados no cenário musical brasileiro daquele período, sendo o primeiro dono de uma loja de instrumentos musicais e editora, a Casa Arthur Napoleão que incentivou durante muitos anos a música brasileira. O segundo, além de ter sido o autor do Hino de Proclamação da República, foi também um dos renovadores do ensino musical no Brasil no início do século XX.

Por ser um empreendimento dirigido por músicos, ou talvez porque os eventos musicais na corte carioca ocorressem com mais frequência, a música é que ocupou a maior parte das páginas do periódico, no entanto, houve espaço para as belas artes e o teatro também.

A Revista Musical e de Bellas artes foi publicada durante dois anos: 1879 e 1880. Tinha oito páginas, sendo que a última era sempre destinada para publicidade em torno da música, seja de estabelecimentos ligados à música, venda ou reparo de instrumentos, ou ainda oferecimento de aulas com profissionais de diversos instrumentos. No corpo da revista existiram colunas como: Notas Biográficas, Noticiário Estrangeiro, Chronica Local, A música na América, Variedades, Instrumentos, Notas de Falecimento, Esthética Positiva, entre outros artigos que tinha por título a temática da qual se trataria como por exemplo o nome de uma obra, ou sobre a Academia de Bellas Artes. 
Em seu primeiro ano a revista foi semanal, no ano seguinte passou a ser publicada quinzenalmente pelos motivos esclarecidos no seu primeiro número do ano II:

\begin{abstract}
“A reconhecia apathia de nossa vida artística no Rio de Janeiro, torna difficil, para não dizer inútil, a existência de semanário nos mezes em que a nossa cidade é absolutamente desprovida de theatro lyrico, concertos e outras festividades que têm relação com a arte musical. Poderíamos é verdade insistir no programma a principio adoptado, enchendo a nossa folha semanal com artigos, noticias de origem estrangeira e logares communs de qualquer genero, com tanto que encobrissemos de caracteres as oito alvas paginas de nossa revista. A questão, porém, não está em escrever dezeseis columnas; mas sim em tornar o jornal agradável, interessante e cheio de novidades. A pratica demonstrou-nos claramente que é isso completamente impossível, sobretudo nos mezes de estação calmosa.

Querendo pois obviar a este inconveniente de maneira que nenhum prejuízo soffressem os nossos leitores, resolvemos pulicar a Revista Musical quinzenalmente, sendo apenas semanal nos mezes de temporada lyrica. (...)"
\end{abstract}

No ano 1880 a revista contou com a colaboração de Oscar Guanabarino, com uma coluna sobre música e com Alfredo D’Escragnolle Taunay, pai do historiado Alfonso Taunay. As colunas voltadas para as questões de belas artes não eram assinadas ou traziam psedônimos como Mirandola, Fromentin, A. C. ou Savarin. Todavia houve dois casos em que os artigos com essa temática foram assinados: o primeiro foi no número quarenta e oito do ano I, nas páginas quatro e cinco, um artigo cujo título foi A Rotina na Arte, assinado por Charles Gounod. No artigo Gounod discute a atuação do crítico e faz uma comparação entre a crítica musical e a crítica da pintura. Ele defende que a pintura por ser uma expressão que não exigiria intermediários para chegar ao público, diferentemente da música a qual exige a interpretação dos músicos, além do fato de uma pintura poder ser admirada pelo tempo que o expectador desejar, teria esta então uma maior vantagem em relação a crítica musical. $O$ artigo é claramente uma crítica aos críticos da música.

O outro caso de um artigo assinado foi feito por Pedro Laurent e teve o título: Resumo da História da Arte Antiga na Grécia e em Roma. O artigo foi publicado em quatro fragmentos, sendo o primeiro artigo no número cinquenta do ano I e a conclusão no número um do ano II. No primeiro parágrafo o autor do texto levanta a questão do desconhecimento da história da arte antiga e destaca a figura de Winckelmann: "Por muito tempo, a história da arte antiga que deve os primeiros esclarecimentos ao celebre e edudito crítico allemão Winckelmann, nascido em 1717 e fallecido em 1768, e que não é conhecida, foi posta de parte pela ignorancia geral dos monumentos mais importantes da antiguidade." E segue ainda destacando o papel dos restauradores na afirmação dos erros: "outra causa contribuiu 
para persistirem essas idéias falsas sobre a arte antiga, referimo-nos sobre á singular mania, no tempo da Renascença, quanto á restauração dos legados artísticos da Grécia e de Roma." O texto segue aludindo de maneira bastante descritiva as diversas realizações Gregas e Romanas na pintura, na arquitetura, na decoração e na criação de jardins. O tom do texto é de defesa dessa produção ao mesmo tempo em que busca informar aos leitores de sua existência.

Um conjunto de textos como esses nos indica uma preocupação que vai além de simplesmente informar, ela também visa educar o público para uma produção artística considerada fundadora da arte e ao mesmo tempo de difícil acesso, já que a grande maioria de seus exemplares se encontrariam na Europa.

A imprensa e principalmente alguns dos periódicos que tratavam de temas culturais como a Revista Illustrada, demonstravam claramente esse objetivo de formar um público, de dar condições para que a população apreciasse um determinado tipo de arte. É claro que não era uma escolha aleatória, mas sim pautada nos critérios dos responsáveis por essas publicações. Com a Revista Musical não foi diferente, um artigo como o de Laurente defende uma aproximação da arte Grega e Romana antiga como pressuposto para que se conheça a arte livre de "concepções extravagantes, monstruosas e sobrenaturaes."

Uma outra temática que esteve muito presente nas páginas da Revista Musical e de Bellas Artes foi a Academia Imperial de Bellas Artes. Em seu número 10, ao comentar a abertura da Exposição Geral da Academia, faria algumas provocações à Academia:

\footnotetext{
"Revelará ella uma evolução artística, que transforme completamente a nossa esthetica, que não tem tido, entre nós outro norte senão a convenção?

Indicará ella qual a tendência idealista ou realista da nova geração de artistas que ha de vir substituir Victor Meirelles, o falecido Motta, e muitos outros que por tantos annos têm occupado a atenção do Brasil com as suas magníficas composições?

Os discipulos pensionistas, ao chegar do estrangeiro, trouxeram nos seus saccos de viagem, alguma idéa nova que rasgue novos horizontes á arte brasileira, e que ponha de lado idéas e processos rotineiros adoptados até aqui?

A academia de bellas artes terá feito escola?

Imprimirá ella os seus alunos discipulos essa feição uniforme, rigida e, em melhores termos: academica, que, que levada ao extremo, tão condemnada tem sido nos outros paizes?" (N.10, ano I, p.1)
}

As inúmeras indagações com as quais o texto foi construído já poderia ser um indicativo de que a revista duvidaria da competência do ensino oferecido pela academia. A leitura parece confirmar tal perspectiva. Fala-se de uma academia baseada em convenções, de uma necessidade de 
mudança e renovação, questionam-se as práticas da academia consideradas demasiado atrasadas, sendo inclusive condenadas em outros lugares.

Embora tenha durado pouco, a Revista Musical e de Bellas Artes se impôs como um espaço de crítica e questionamento da AIBA. Além disso, defendeu um projeto para a construção de uma arte nacional. 